\title{
Monitoring of Heavy Metal Content in Fruits and Vegetables Collected from Production and Market Sites in the Misurata Area of Libya
}

\author{
M. A. Elbagermi, ${ }^{1}$ H. G. M. Edwards, ${ }^{2}$ and A. I. Alajtal ${ }^{1}$ \\ ${ }^{1}$ Department of Chemistry, Faculty of Science, University of Misurata, P.O. Box 1338, Misurata, Libya \\ ${ }^{2}$ Raman Spectroscopy Group, University Analytical Centre, Division of Chemical and Forensic Sciences, University of Bradford, \\ West Yorkshire BD7 1DP, UK
}

Correspondence should be addressed to M. A. Elbagermi, m.elbagermi@yahoo.co.uk

Received 24 January 2012; Accepted 16 February 2012

Academic Editors: I. Djerdj, H. Kara, and I. Zhukov

Copyright ( $) 2012$ M. A. Elbagermi et al. This is an open access article distributed under the Creative Commons Attribution License, which permits unrestricted use, distribution, and reproduction in any medium, provided the original work is properly cited.

\begin{abstract}
The content of lead $(\mathrm{Pb})$, copper $(\mathrm{Cu})$, zinc $(\mathrm{Zn})$, cobalt $(\mathrm{Co})$, nickel $(\mathrm{Ni})$, and cadmium $(\mathrm{Cd})$ in some selected fruits and vegetables from the Misurata City Market, Libya, were measured using atomic absorption spectrophotometry. The results of this study showed that the average concentrations detected ranged from 0.02 to $1.824,0.75$ to $6.21,0.042$ to $11.4,0.141$ to $1.168,0.19$ to 5.143 , and 0.01 to $0.362 \mathrm{mg} / \mathrm{kg}$ for $\mathrm{Pb}, \mathrm{Cu}, \mathrm{Zn}, \mathrm{Co}, \mathrm{Ni}$, and $\mathrm{Cd}$, respectively. The highest mean levels of $\mathrm{Pb}, \mathrm{Cu}, \mathrm{Zn}, \mathrm{Co}, \mathrm{Ni}$ and $\mathrm{Cd}$ were detected in mango, melon, spinach, banana, mango, and mango fruits, respectively. The levels of these metals found in our study are compared with those reported for similar fruits and vegetables from some other parts of the world. The daily human intakes of $\mathrm{Pb}, \mathrm{Cu}, \mathrm{Zn}, \mathrm{Co}, \mathrm{Ni}$, and $\mathrm{Cd}$ ascribed to a diet of fruits and vegetables in this region have also been estimated.
\end{abstract}

\section{Introduction}

The effect of heavy metal contamination of fruit and vegetables cannot be underestimated as these foodstuffs are important components of human diet. Fruit and vegetables are rich sources of vitamins, minerals, and fibers and also have beneficial antioxidative effects. However, the intake of heavy metal-contaminated fruit and vegetables may pose a risk to human health; hence the heavy metal contamination of food is one of the most important aspects of food quality assurance [1-3]. Heavy metals, in general, are not biodegradable, have long biological half-lives, and have the potential for accumulation in different body organs, leading to unwanted side effects $[4,5]$. Plants take up heavy metals by absorbing them from airborne deposits on the parts of the plants exposed to the air from the polluted environments as well as from contaminated soils through root systems. Also, the heavy metal contamination of fruit and vegetables may occur due to their irrigation with contaminated water [6].
Demirezen and Aksoy [7] have investigated the concentrations of some heavy metals in different vegetables grown in various parts of Turkey. The levels of heavy metals (lead, cadmium, copper, and zinc) have been examined in selected fruits and vegetables sold in local Egyptian markets [1]. Fytianos et al. [8] studied the contents of heavy metals in vegetables grown in an industrial area of Northern Greece, and Sobukola et al. [9] investigated the concentrations of some heavy metals in fruits and leafy vegetables from selected markets in Lagos, Nigeria.

Based on their persistence and cumulative behavior as well as the probability of potential toxicity effects, the absorption of heavy metals in human diets as a result of the consumption of vegetables and fruits means that there is a requirement for the analysis of food items to ensure that the levels of trace heavy metals meet the agreed international standards. This is particularly important for farm products from parts of the world where only limited data on the heavy metal content are available. Knowledge of the contamination 
of fruit and vegetables with heavy metals from the Misurata areas of Libya has not yet been established; therefore, the present study was undertaken with the aim to compare and investigate the concentration of some specific heavy metals $(\mathrm{Pb}, \mathrm{Cd}, \mathrm{Zn}, \mathrm{Cu}, \mathrm{Co}$, and $\mathrm{Ni})$ found in some selected fruit and vegetables from this region.

1.1. Allowable Limit of Heavy Metals. Safe values for copper, lead, and cadmium in fruit and vegetables recommended by the $\mathrm{WHO} / \mathrm{FAO}$ are $40,0.3$, and $0.2 \mathrm{mg} / \mathrm{kg}$, respectively [10].

\section{Material and Methods}

2.1. Sample Collection. A total of 250 samples of fruit and vegetable produce were purchased from several local suppliers and markets in Misurata City, Libya, during 2010. The sampling comprised $2 \mathrm{~kg}$ for each commodity sold in each district and was considered to be quite representative since the districts were scattered randomly throughout the city; for the analysis, only the edible portions of each fruit and vegetable were included, and additionally the bruised or rotten parts were removed.

2.2. Sample Preparation and Treatment. Subsamples (each of $1 \mathrm{~kg}$ ) were taken at random from the composite sample $(10 \mathrm{~kg})$ and were processed for analysis by the dry-ashing method. The samples were first oven-dried at $105^{\circ} \mathrm{C}$ for $24 \mathrm{~h}$. The dried samples were then powdered manually in a grinder and were subjected to analysis for their heavy metal content.

Powdered samples (14 g each), with three replicates taken for each food item, were accurately weighed and placed in a silica crucible, and few drops of concentrated nitric acid were added to the solid as an aid to ashing. The dry-ashing process was carried out in a muffle furnace by stepwise increase of the temperature up to $550^{\circ} \mathrm{C}$ and the samples left to ash at this temperature for $6 \mathrm{~h} \mathrm{[16].}$

The ash was kept in desiccators and then rinsed with $3 \mathrm{~N}$ hydrochloric acid. The ash suspension was filtered into a $50 \mathrm{~mL}$ volumetric flask through Whatman No. 1 filter paper, and the volume was made up to the mark with $3 \mathrm{~N}$ hydrochloric acid.

2.3. Standards. Standard solutions of the heavy metals, namely, lead $(\mathrm{Pb})$, cadmium $(\mathrm{Cd})$, copper $(\mathrm{Cu})$, cobalt $(\mathrm{Co})$, nickel $(\mathrm{Ni})$, and zinc $(\mathrm{Zn})$, were provided by Merck (Darmstadt, Germany). The standards were prepared from the individual $1000 \mathrm{mg} / \mathrm{L}$ standards (Merck) supplied in $0.1 \mathrm{~N}$ $\mathrm{HNO}_{3}$. A series of working standards were prepared from these standard stock solutions.

2.4. Quality Assurance. Appropriate quality assurance procedures and precautions were taken to ensure the reliability of the results. Samples were carefully handled to avoid crosscontamination.

Glassware was properly cleaned, and reagents used were of analytical grades. Deionized water was used throughout the study. Reagent blank determinations were used to apply corrections to the instrument readings. For validation of the analytical procedure, repeated analyses of the samples against internationally certified plant standard reference material (SRM) of the National Institute of Standard and Technology were used, and the results were found to lie within $\pm 1 \%$ of the certified values.

2.5. Daily Intake of Heavy Metals through Fruits and Vegetables. The daily intake of heavy metals through the consumption of fruit and vegetables tested was calculated according to the equation [17]:

$$
\begin{aligned}
& \text { Daily intake of heavy metals }\left(\frac{\mu \mathrm{g}}{\mathrm{day}}\right) \\
& =\text { [Daily fruit or vegetable consumption } \\
& \quad \times \text { fruit or vegetable heavy metal concentration]. }
\end{aligned}
$$

The daily fruit and vegetable consumption was obtained through a formal survey conducted in the study area. An interview of 30 persons of the 25-50 years age group and in the range $63-78 \mathrm{~kg}$ body weight was conducted at each market site regarding their daily consumption rate of the fruit and vegetables tested. Each person represented a household having $\geq 6$ individuals, and, thus, a total of 180 persons or more were effectively sampled. An average consumption rate of each fruit and vegetable per person per day was calculated from these data.

2.6. Flame Atomic Absorption Analysis. Analysis for the heavy metals of interest was performed using atomic absorption spectrometry (180-30 Hitachi spectrometer). Measurements were made using standard hollow cathode lamps for $\mathrm{Pb}, \mathrm{Cd}$, $\mathrm{Zn}, \mathrm{Cu}, \mathrm{Co}$, and $\mathrm{Ni}$. The limit of detection (LOD) of the analytical method for each metal was calculated as being triple the standard deviation of a series of measurements for each solution, the concentration of which is distinctly detectable above the background level. These values were $0.001,0.001,0.001,0.003,0.001$, and $0.002 \mathrm{mg} / \mathrm{kg}$ for $\mathrm{Pb}$, $\mathrm{Cd}, \mathrm{Zn}, \mathrm{Cu}, \mathrm{Co}$, and $\mathrm{Ni}$, respectively. Also, the limit of quantification (LOQ) of the element was determined; these were calculated as $0.003,0.003,0.003,0.01,0.003$, and $0.007 \mathrm{mg} / \mathrm{kg}$ for $\mathrm{Pb}, \mathrm{Cd}, \mathrm{Zn}, \mathrm{Cu}, \mathrm{Co}$, and $\mathrm{Ni}$, respectively. The standard operating conditions for the analysis of heavy metals using atomic absorption spectrometry used in our experiments are given in Table 1.

\section{Results and Discussion}

The present study reports on the heavy metal content of $\mathrm{Pb}, \mathrm{Cd}, \mathrm{Zn}, \mathrm{Cu}, \mathrm{Co}$, and $\mathrm{Ni}$ determined in selected fruit and vegetables collected from production and market sites in the Misurata area of Libya. The observed concentrations of $\mathrm{Pb}, \mathrm{Cd}, \mathrm{Zn}, \mathrm{Cu}, \mathrm{Co}$, and $\mathrm{Ni}$ in the fruit and vegetables were compared with the recommended limit as established by the FAO/WHO in 1999 to assess the levels of food contamination.

The mean concentrations and range of heavy metals found in fresh fruit and vegetables sampled from the local markets in Misurata City, Libya, are summarized in Table 2 
TABLE 1: Standard operating conditions for the analysis of heavy metals using atomic absorption spectrometry.

\begin{tabular}{|c|c|c|c|c|}
\hline Metals & Wavelength $(\mathrm{nm})$ & Lamp current (mA) & Flame & Slit width $(\mathrm{mm})$ \\
\hline $\mathrm{Pb}$ & 283.312 & 283.312 & \multirow{6}{*}{ Air-acetylene } & 0.7 \\
\hline $\mathrm{Cd}$ & 228.86 & 228.86 & & 0.7 \\
\hline $\mathrm{Cu}$ & 324.830 & 324.830 & & 0.7 \\
\hline $\mathrm{Zn}$ & 213.920 & 213.920 & & 0.7 \\
\hline Co & 240.730 & 240.730 & & 0.2 \\
\hline $\mathrm{Ni}$ & 232.030 & 232.030 & & 0.2 \\
\hline
\end{tabular}

TABLE 2: Concentration of heavy metals $(\mathrm{mg} / \mathrm{kg}$ or $\mathrm{ppm})$ in fruits and vegetables.

\begin{tabular}{lccccccc}
\hline \multirow{2}{*}{ Commodity } & $\begin{array}{c}\text { Moisture } \\
\text { content (\%) }\end{array}$ & $\mathrm{Pb}$ & $\mathrm{Cd}$ & $\mathrm{C}$ Concentrations of metals & $\mathrm{Cu}$ & $\mathrm{Co}$ & $\mathrm{Ni}$ \\
\hline \multicolumn{7}{c}{} & \multicolumn{7}{c}{ Fruits } \\
\hline Banana & 75.0 & $0.10 \pm 0.01$ & $0.05 \pm 0.01$ & $6.34 \pm 0.57$ & $3.21 \pm 0.66$ & $1.168 \pm 0.559$ & $1.316 \pm 0.635$ \\
Peach & 90.3 & $0.25 \pm 0.05$ & $0.02 \pm 0.01$ & $5.87 \pm 0.43$ & $1.87 \pm 0.25$ & $1.049 \pm 0.203$ & $1.119 \pm 0.220$ \\
Orange & 88.5 & $0.20 \pm 0.04$ & $0.03 \pm 0.02$ & $2.15 \pm 0.01$ & $1.25 \pm 0.11$ & $0.763 \pm 0.379$ & $1.099 \pm 0.368$ \\
Strawberries & 90.1 & $0.53 \pm 0.20$ & $0.01 \pm 0.02$ & $1.32 \pm 3.12$ & $3.14 \pm 0.58$ & $0.272 \pm 0.026$ & $1.818 \pm 0.103$ \\
Watermelon & 95.4 & $0.5 \pm 0.20$ & $0.03 \pm 0.02$ & $5.11 \pm 0.15$ & $1.19 \pm 1.00$ & $0.141 \pm 0.091$ & $0.597 \pm 0.280$ \\
Melon & 92.5 & $0.25 \pm 0.02$ & $0.03 \pm 0.01$ & $8.24 \pm 0.78$ & $6.21 \pm 0.10$ & $0.340 \pm 0.014$ & $0.645 \pm 0.195$ \\
Apple & 85.0 & $0.2 \pm 0.06$ & $0.06 \pm 0.03$ & $2.34 \pm 0.13$ & $1.50 \pm 0.10$ & $0.437 \pm 0.062$ & $1.00 \pm 0.145$ \\
Grape & 89.1 & $0.4 \pm 0.03$ & $0.05 \pm 0.02$ & $1.33 \pm 0.21$ & $2.13 \pm 0.19$ & $0.521 \pm 0.022$ & $0.631 \pm 0.014$ \\
Mango & 82.1 & $1.824 \pm 0.821$ & $0.362 \pm 0.03$ & $0.635 \pm 0.055$ & $3.186 \pm 0.356$ & $0.561 \pm 0.128$ & $5.143 \pm 0.517$ \\
\hline & & \multicolumn{7}{c}{ Vegetables } & & & \\
\hline Tomatoes & 94.0 & $0.511 \pm 0.081$ & $0.250 \pm 0.025$ & $8.427 \pm 0.635$ & $2.245 \pm 0.050$ & $0.45 \pm 0.011$ & $0.20 \pm 0.052$ \\
Onion & 86.4 & $0.14 \pm 0.07$ & $0.02 \pm 0.00$ & $11.4 \pm 0.64$ & $1.49 \pm 0.06$ & $0.51 \pm 0.023$ & $0.32 \pm 0.034$ \\
Potatoes & 75.2 & $0.02 \pm 0.05$ & $0.02 \pm 0.01$ & $7.11 \pm 0.54$ & $0.75 \pm 0.21$ & $0.55 \pm 0.018$ & $0.25 \pm 0.032$ \\
Green pepper & 91.3 & $0.47 \pm 0.03$ & $0.07 \pm 0.01$ & $0.042-0.052$ & $2.97 \pm 0.33$ & $0.34 \pm 0.015$ & $0.19 \pm 0.016$ \\
Carrot & 85.6 & $0.21 \pm 0.05$ & $0.12 \pm 0.02$ & $3.61 \pm 0.5$ & $5.00 \pm 0.11$ & $0.54 \pm 0.017$ & $0.21 \pm 0.031$ \\
Cucumber & 94.3 & $0.10 \pm 0.02$ & $0.20 \pm 0.04$ & $9.65 \pm 0.86$ & $5.75 \pm 0.61$ & $0.62 \pm 0.022$ & $0.22 \pm 0.061$ \\
Spinach & 89.9 & $0.32 \pm 0.02$ & $0.27 \pm 0.03$ & $16.83 \pm 2.82$ & $5.32 \pm 0.54$ & $0.54 \pm 0.021$ & $0.26 \pm 0.065$ \\
\hline
\end{tabular}

and Figures 1, 2, 3, and 4. The heavy metal concentrations determined were based on sample dry weight. The results showed that the levels of $\mathrm{Pb}$ in all commodities ranged between $0.02 \mathrm{mg} / \mathrm{kg}$ in potatoes and 1.824 in mangos. The $\mathrm{Cd}$ content ranged from $0.01 \mathrm{mg} / \mathrm{kg}$ in strawberries to $0.362 \mathrm{mg} / \mathrm{kg}$ in mangos.

Within the selected fruit, the highest concentrations of $\mathrm{Pb}$ were noticed in mangos followed by strawberries, watermelons, grapes, peaches, melons, apples, and oranges in decreasing concentrations, whereas in the vegetables studied the highest concentration of $\mathrm{Pb}$ was found in tomatoes followed by green peppers, spinach, carrots, onions, and potatoes. The higher levels of heavy metal contamination found in some fruit and vegetables could be closely related to the pollutants in irrigation water, farm soil, and pesticides or alternatively could be due to pollution from traffic on the the highways [18]. Comparison of the metal content in fruit and vegetables in some other parts of the world is shown in Table 4 and revealed that the levels are generally comparable in Libya and elsewhere. On the other hand, the concentration of $\mathrm{Pb}$ in apples was significantly lower than that detected in India, Egypt, and Turkey [11-13]. In contrast, the concentration of $\mathrm{Pb}$ in potatoes was found to be higher than that found in the USA, for example [15].

Apart from its function as a biocatalyst, $\mathrm{Cu}$ is necessary for body pigmentation, for the maintenance of a healthy central nervous system, and for the prevention of anaemia, and it is interrelated with the function of $\mathrm{Zn}$ and $\mathrm{Fe}$ in the body [19].

Like $\mathrm{Cu}, \mathrm{Zn}$ is an essential element for plants and animals, but only a small increase in its level may cause interference with physiological processes. The presence of $\mathrm{Zn}$ seems to be essential to neutralize the toxic effects of $\mathrm{Cd}$. In this study, the maximum quantity of zinc was detected in melons $(8.24 \mathrm{mg} / \mathrm{kg})$ while mangos had the lowest concentration $(0.635 \mathrm{mg} / \mathrm{kg})$. Zn levels in this study showed a divergence from those reported in other countries; its levels were here found to be higher in vegetables and lower in fruits when compared with similar samples in other countries, as shown in Table 4.

The exposure of consumers and the related health risks are usually expressed in terms of the provisional tolerable daily intake (PTDI) [20]. The FAO/WHO have set a limit for 
TABLE 3: Estimation of heavy metal intake through consumption of fruits and vegetables in Misurata, Libya.

\begin{tabular}{lcccccccccccc}
\hline $\begin{array}{l}\text { Foodstuffs } \\
\text { (g/person/day) }\end{array}$ & $\mathrm{Pb}$ & $\begin{array}{c}\text { Intake } \\
\mu \mathrm{g} / \mathrm{day}\end{array}$ & $\mathrm{Cd}$ & $\begin{array}{c}\text { Intake } \\
\mu \mathrm{g} / \mathrm{day}\end{array}$ & $\mathrm{Zn}$ & $\begin{array}{c}\text { Intake } \\
\mathrm{mg} / \mathrm{day}\end{array}$ & $\mathrm{Cu}$ & $\begin{array}{c}\text { Intake } \\
\mathrm{mg} / \mathrm{day}\end{array}$ & $\mathrm{Co}$ & $\begin{array}{c}\text { Intake } \\
\mu \mathrm{g} / \mathrm{day}\end{array}$ & $\mathrm{Ni}$ & $\begin{array}{c}\text { Intake } \\
\mathrm{mg} / \mathrm{day}\end{array}$ \\
\hline Fruits (78) & 0.473 & 36.89 & 0.071 & 5.54 & 3.7 & 0.288 & 2.63 & 0.205 & 0.58 & 45.24 & 1.49 & 0.116 \\
Vegetables (98) & 0.25 & 24.8 & 0.14 & 13.3 & 8.15 & 0.8 & 3.36 & 0.33 & 0.51 & 49.7 & 0.24 & 0.0231 \\
\hline
\end{tabular}

TABLE 4: Levels of metals in fruits and vegetables in previously published results from other parts of the world [11-15].

\begin{tabular}{lcccccc}
\hline sample & $\mathrm{Pb}$ & $\mathrm{Cd}$ & $\mathrm{Zn}$ & $\mathrm{Cu}$ & $\mathrm{Co}$ & $\mathrm{Ni}$ \\
\hline Banana & 7.46 & 13.36 & 45.64 & 14.19 & 3.00 & 25.40 \\
Apple & 23.48 & 8.39 & 35.88 & 6.34 & 185.90 & 6.23 \\
Mango & 67.20 & 16.9 & 18.29 & 7.83 & - \\
Tomato & 0.26 & 0.01 & 0.09 & 0.09 & - \\
Onion & 0.06 & 0.07 & 2.10 & 0.64 & - \\
Potatoes & 0.009 & 0.031 & & - \\
\hline
\end{tabular}

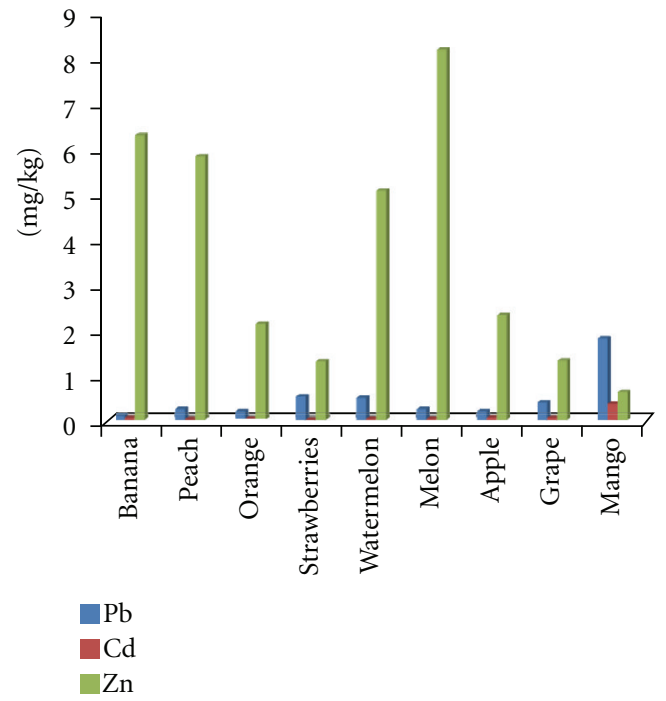

FIgURE 1: Concentration of $\mathrm{pb}, \mathrm{Cd}$, and $\mathrm{ZN}$ in fruits.

the heavy metal intake based on body weight for an average adult, namely, $60 \mathrm{~kg}$ body weight. The average diets per person per day of vegetables and fruits are 98 and $78 \mathrm{~g}$, respectively. If the mean levels of $\mathrm{Pb}(0.473 \mathrm{mg} / \mathrm{kg})$, $\mathrm{Cd}(0.071 \mathrm{mg} / \mathrm{kg}), \mathrm{Cu}(2.63 \mathrm{mg} / \mathrm{kg}), \mathrm{Zn}(3.7 \mathrm{mg} / \mathrm{kg})$, Co $(0.58 \mathrm{mg} / \mathrm{kg})$, and $\mathrm{Ni}(1.497 \mathrm{mg} / \mathrm{kg})$ found here are consumed daily, the contribution of heavy metal intake for an average human being from the fruit diet is $36.89 \mu \mathrm{g}, 5.54 \mu \mathrm{g}$, $0.205 \mathrm{mg}, 0.288 \mathrm{mg}, 45.24 \mu \mathrm{g}$, and $0.116 \mathrm{mg}$, respectively. In case of vegetables, if the consumed daily mean levels of $\mathrm{Pb}$, $\mathrm{Cd}, \mathrm{Zn}, \mathrm{Cu}, \mathrm{Co}$, and $\mathrm{Ni}$ are $0.25,0.14,8.15,3.36,0.51$ and $0.24 \mathrm{mg} / \mathrm{kg}$, respectively, the corresponding estimated daily intake will be $24.8 \mu \mathrm{g}, 13.3 \mu \mathrm{g}, 0.8 \mathrm{mg}, 0.33 \mathrm{mg}, 49.7 \mu \mathrm{g}$, and $0.0231 \mathrm{mg}$, respectively as shown in Table 3 .

It can therefore be concluded that our estimated daily intakes for the heavy metals studied here are below those reported by the FAO/WHO, which have set a PTDI limit for the heavy metal intake based on body weight for an average

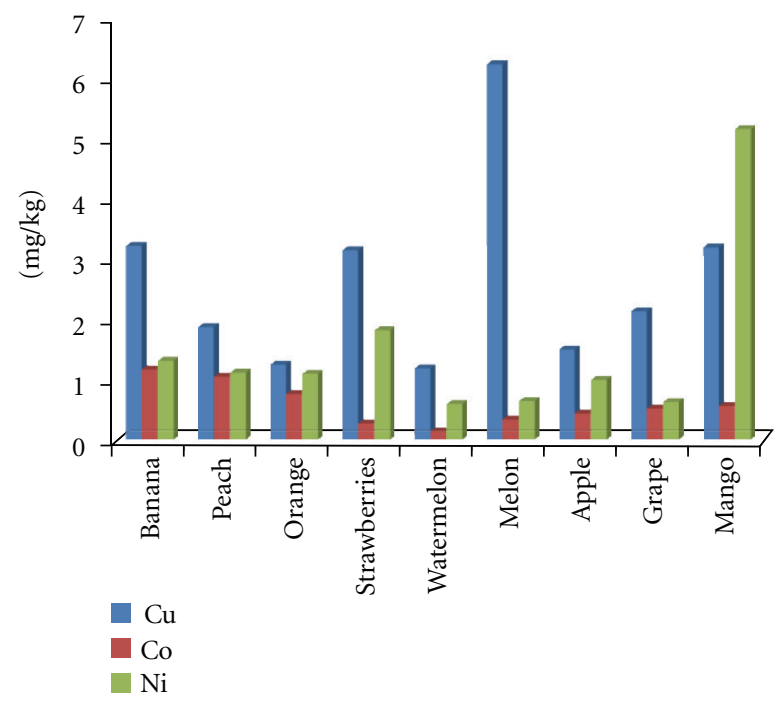

Figure 2: Concentration of $\mathrm{Cu}, \mathrm{Co}$, and $\mathrm{Ni}$ in fruits.

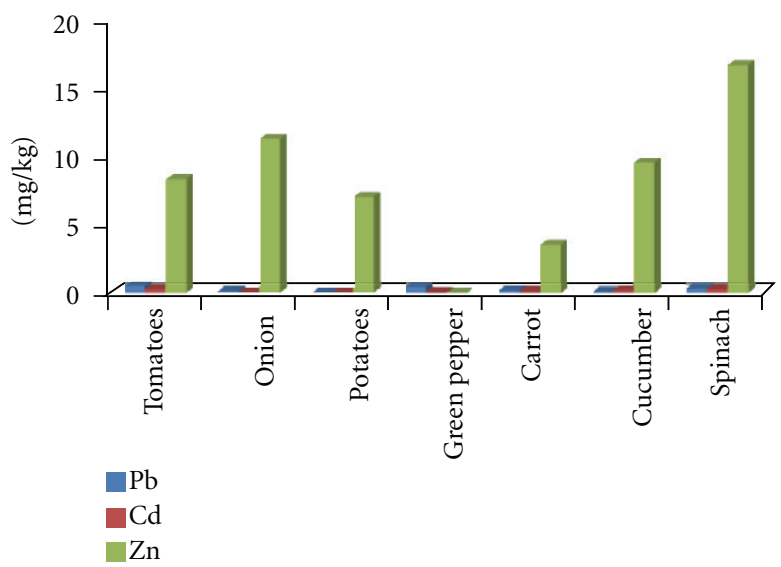

Figure 3: Concentration of $\mathrm{pb}, \mathrm{Cd}$, and $\mathrm{ZN}$ in vegetables. 


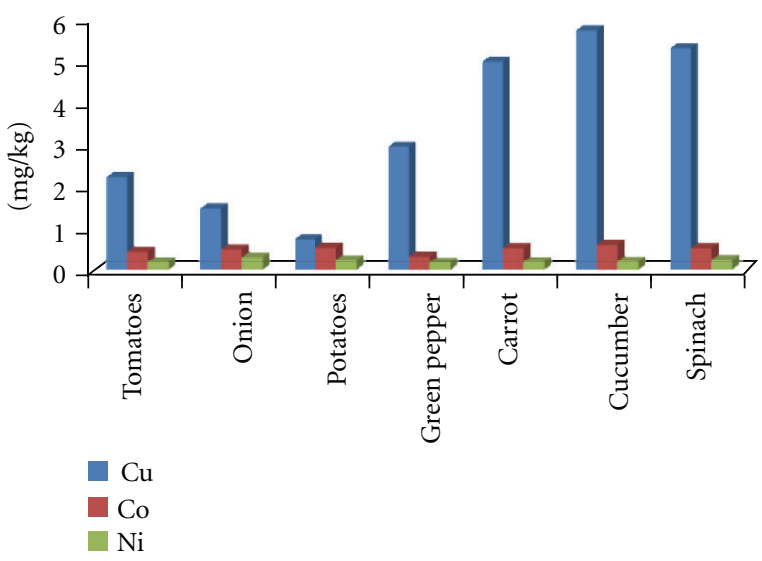

Figure 4: Concentration of $\mathrm{Cu}, \mathrm{Co}$, and $\mathrm{Ni}$ in vegetables.

adult (60 kg body weight) for $\mathrm{Pb}, \mathrm{Cd}, \mathrm{Cu}$, and $\mathrm{Zn}$ as $214 \mu \mathrm{g}$, $60 \mu \mathrm{g}, 3 \mathrm{mg}$, and $60 \mathrm{mg}$, respectively [20].

\section{Conclusion}

In conclusion, the results reported here confirm that the fruit and vegetables collected from chosen production and market sites in the Misurata area of Libya contained measured heavy metal contents within the safe limits prescribed by the WHO in 1999. This is an important result as human health is directly affected by ingestion of fruit and vegetables; the biomonitoring of trace elements in fleshy fruits needs to be continued because these are the main sources of food for humans in many parts of the world.

\section{References}

[1] M. A. Radwan and A. K. Salama, "Market basket survey for some heavy metals in Egyptian fruits and vegetables," Food and Chemical Toxicology, vol. 44, no. 8, pp. 1273-1278, 2006.

[2] X. Wang, T. Saro, B. Xing, and S. Tao, Science of The Total Environment, vol. 330, no. 1-3, p. 28, 2005.

[3] S. Khan, Q. Cao, Y. M. Zheng, Y. Z. Huang, and Y. G. Zhu, "Health risks of heavy metals in contaminated soils and food crops irrigated with wastewater in Beijing, China," Environmental Pollution, vol. 152, no. 3, pp. 686-692, 2008.

[4] L. Järup, "Hazards of heavy metal contamination," British Medical Bulletin, vol. 68, pp. 167-182, 2003.

[5] N. G. Sathawara, D. J. Parikh, and Y. K. Agarwal, "Essential heavy metals in environmental samples from Western India," Bulletin of Environmental Contamination and Toxicology, vol. 73, no. 4, pp. 756-761, 2004.

[6] M. S. Al Jassir, A. Shaker, and M. A. Khaliq, "Deposition of heavy metals on green leafy vegetables sold on roadsides of Riyadh City, Saudi Arabia," Bulletin of Environmental Contamination and Toxicology, vol. 75, no. 5, pp. 1020-1027, 2005.

[7] D. Demirezen and A. Aksoy, "Heavy metal levels in vegetables in Turkey are within safe limits for $\mathrm{Cu}, \mathrm{Zn}, \mathrm{Ni}$ and exceeded for Cd and Pb," Journal of Food Quality, vol. 29, no. 3, pp. 252$265,2006$.
[8] K. Fytianos, G. Katsianis, P. Triantafyllou, and G. Zachariadis, "Accumulation of heavy metals in vegetables grown in an industrial area in relation to soil," Bulletin of Environmental Contamination and Toxicology, vol. 67, no. 3, pp. 423-430, 2001.

[9] O. P. Sobukola, O. M. Adeniran, A. A. Odedairo, and O. E. Kajihausa, "Heavy metal levels of some fruits and leafy vegetables from selected markets in Lagos, Nigeria," African Journal of Food Science, vol. 4, no. 2, pp. 389-393, 2010.

[10] A. Husain, Z. Baroon, M. Al-khalafawi, T. Al-Ati, and W. Sawaya, "Toxic metals in imported fruits and vegetables marketed in Kuwait," Environment International, vol. 21, no. 6, pp. 803-805, 1995.

[11] S. E Mahdavian and R. K. Somashekar, Journal of Science, Engineering and Technology, vol. 1, no. 5, p. 17, 2008.

[12] A. E. Mohamed, "Trace element levels in some kinds of dates," Food Chemistry, vol. 70, no. 1, pp. 9-12, 2000.

[13] S. Saracoglu, M. Tuzen, and M. Soylak, "Evaluation of trace element contents of dried apricot samples from Turkey," Journal of Hazardous Materials, vol. 167, no. 1-3, pp. 647-652, 2009.

[14] Z. Parveen, M. I. Khuhro, and N. Rafiq, "Market basket survey for lead, cadmium, copper, chromium, nickel, and zinc in fruits and vegetables," Bulletin of Environmental Contamination and Toxicology, vol. 71, no. 6, pp. 1260-1264, 2003.

[15] J. Pennington, S. Schoen, G. Salmon, B. Young, R. Johnson, and R. W. Marts, "Composition of core foods of the U.S. Food Supply, 1982-1991. III. Copper, manganese, selenium, and iodine," Journal of Food Composition and Analysis, vol. 8, no. 2, pp. 171-217, 1995.

[16] N. T. Crosby, "Determination of metals in foods: a review," Analyst, vol. 102, no. 1213, pp. 225-268, 1977.

[17] Y.-J. Cui, Y.-G. Zhu, R.-H. Zhai et al., "Transfer of metals from soil to vegetables in an area near a smelter in Nanning, China," Environment International, vol. 30, no. 6, pp. 785-791, 2004.

[18] A. O. Igwegbe, H. Belhaj, T. M. Hassan, and A. S. Gibali, "Effect of a Highway'S traffic on the level of lead and cadmium in fruits and vegetables grown along the roadsides," Journal of Food Safety, vol. 13, no. 1, pp. 7-18, 1992.

[19] I. O. Akinyele and O. Osibanjo, "Levels of some trace elements in hospital diets," Food Chemistry, vol. 8, no. 4, pp. 247-251, 1982.

[20] Joint FAO/WHO Expert Committee on Food Additives, "Summary and conclusions," in Proceedings of the 53rd Meeting Joint FAO/WHO Expert Committee on Food Additives, Rome, Italy, June 1999. 


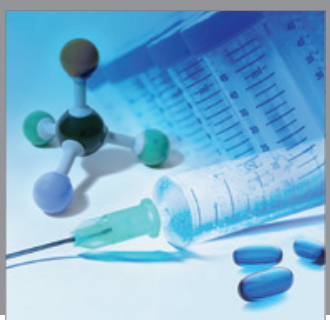

International Journal of

Medicinal Chemistry

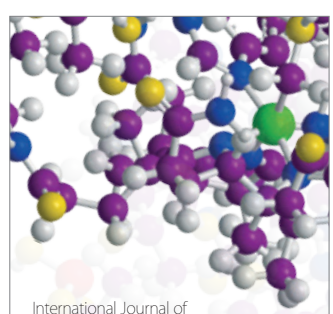

Carbohydrate Chemistry

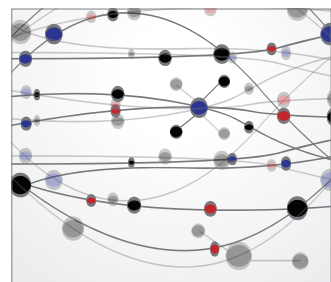

The Scientific World Journal
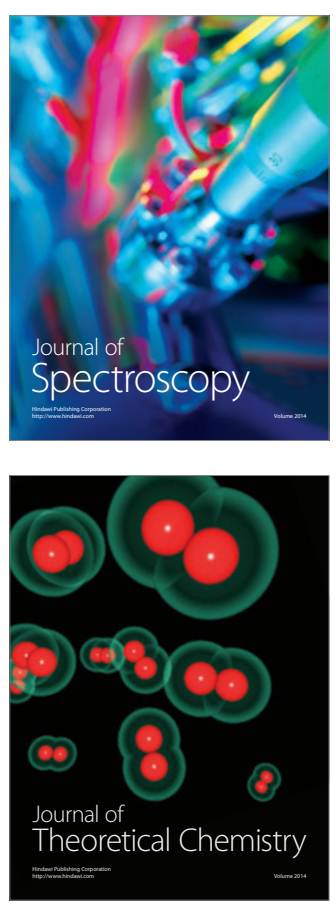
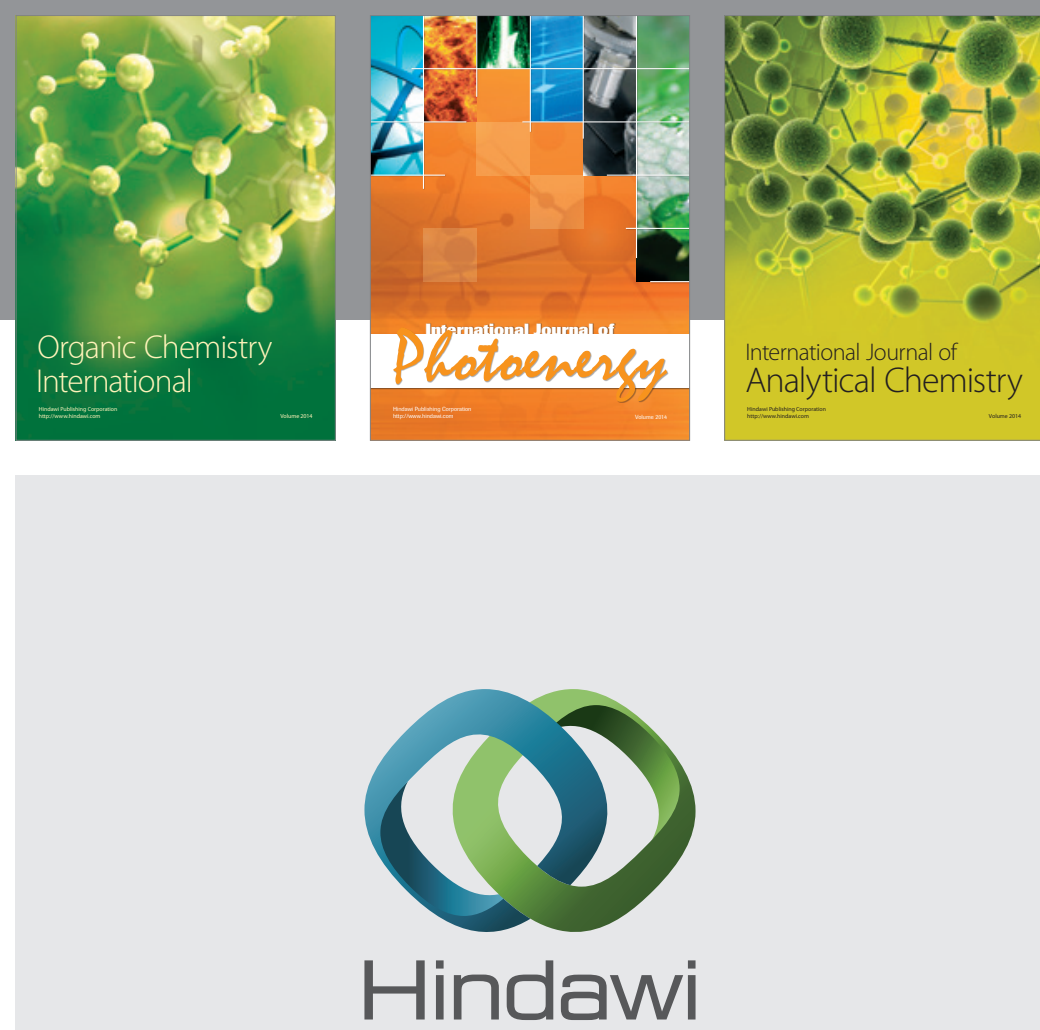

Submit your manuscripts at

http://www.hindawi.com
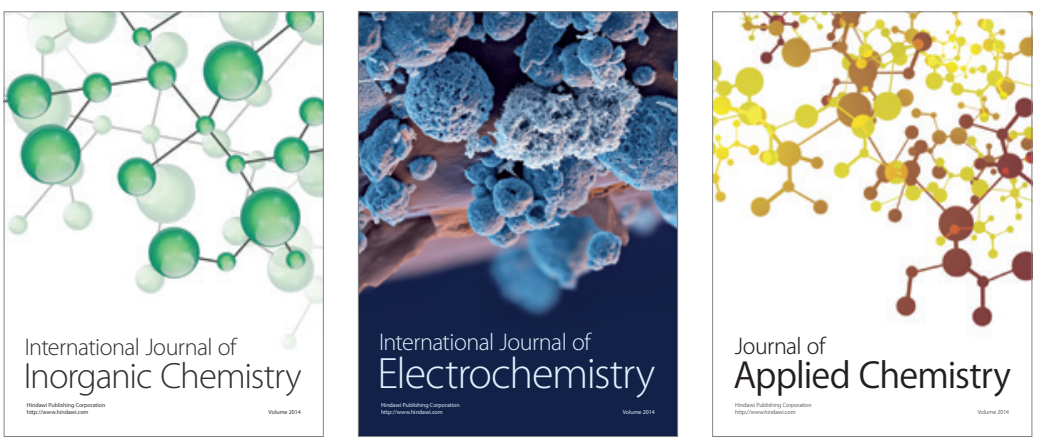

Journal of

Applied Chemistry
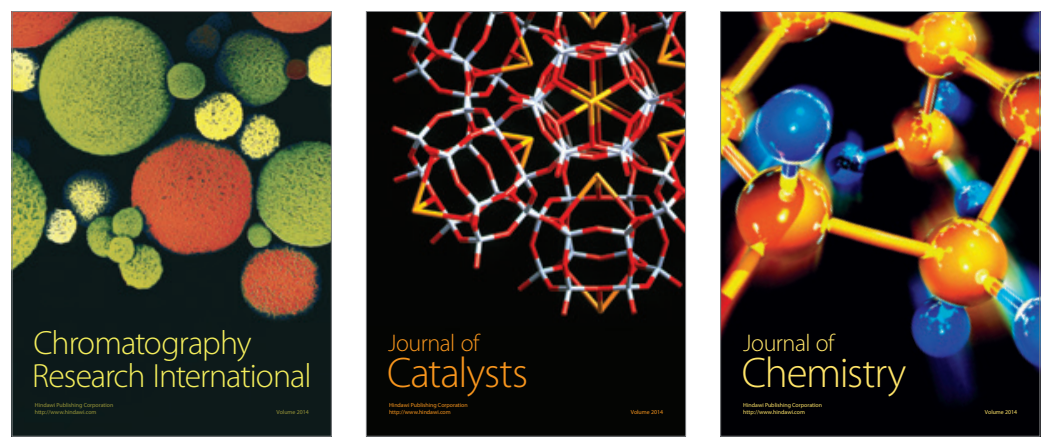
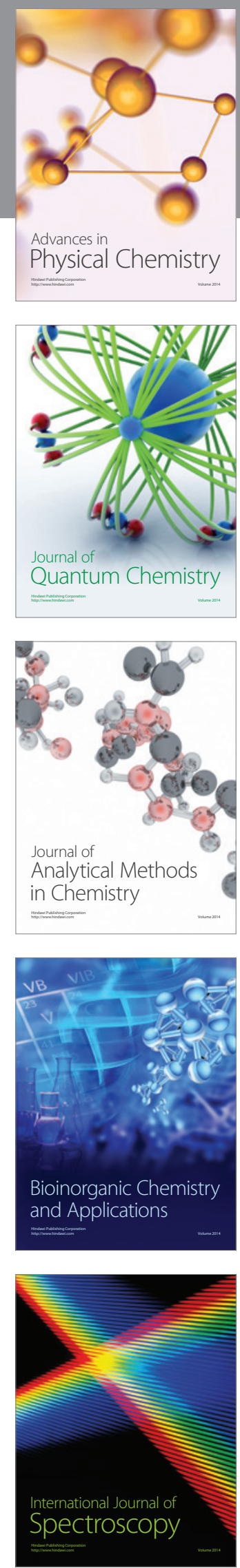